\title{
Review of Coaching Culture in the Times of Change in the UK Housing Associations Sector
}

\author{
Muhammad Tahir Rafique, \\ University of Nottingham, United Kingdom
}

\begin{abstract}
Coaching has grown rapidly in the last twenty years, reflecting increased level of interest in the field. The widespread popularity, however, has been largely attributed to the anecdotal feedback about its effectiveness due to considerable gaps in the empirical research base. The aim of this study is to explore the role of coaching in relation to transformational changes with particular reference to housing association mergers in the UK. As a result of constant merger activity, the largest twenty housing associations own $30 \%$ of the market share and the trend is likely to continue, making the research outcomes useful for future strategic planning of housing association mergers.

The study found that coaching plays an important role in housing association mergers and transformational changes especially in creating a new shared identity and staff integration after housing association mergers. Integration can keep the merged housing associations together, thus reducing the merger failures in the housing associations.
\end{abstract}

Paper type: Research paper

Keywords: Coaching, Mergers, Housing Association, Transformational Change 


\section{Introduction}

This paper discusses the role of coaching in coping with organisational changes related to dynamic developments, such as mergers, in the housing association sector in the UK. Although the relationship between coaching and transformation has been documented (Mezirow, 1991; Griffiths, 2005; Rogers, 2012), the housing association merger perspective remains a neglected area of research in the UK. Recent research shows that currently housing associations manage a far larger number of homes than ever before (Gulliver et al., 2011; Rees et al., 2012) and that the most recent trend is that of mergers. Literature on corporate mergers in general has shown that many mergers fail or at least are highly problematic. These problems include: 'lowered commitment and productivity, increased dissatisfaction and disloyalty, high turnover among key managers, leadership and power struggle among the managers who stay, and, in general, a rise in dysfunctional work-related behaviours at all levels of hierarchy' (Buono and Bowditch, 2003, p. 3). These behaviours are caused by human factors such as stress, uncertainty and anxiety (Mirvis and Marks, 2003). Coaching is regarded as vital resource to lessen stress and manage uncertainty (Rigsby et al., 1998; Grant et al., 2009) during large-scale organisational changes such as mergers and restructures.

The trajectory of housing association development presented in the following quote is opportunistic rather than strategic:

... the rise of housing associations in the past should be seen as incremental and opportunistic. If we stand back far enough to take a long-term view of what is today called social housing, it is arguable that there is a consistent direction of travel, away from the overwhelming municipalist and collectivist dominance of the period from 1919 to 1979 (Malpass, 2009, pp. 116-117).

But, from 1980 onwards, a strategic direction started to evolve as housing associations started to merge with one another. As a result of constant merger activity in the last twenty-five years, average housing associations doubled in size from 955 homes to 1,816 homes, whereas market share amongst the largest twenty housing associations increased from 26 per cent to 30 per cent (Rees et al., 2012). Some larger housing associations own and manage over 50,000 homes, whereas the largest housing group, Sanctuary, through a series of mergers now owns and manages 94,000 properties. With this level of activity, housing association mergers are important. To fully appreciate the housing association merger process, it is important to recognise the interventions used to deal with human factors. This in turn presents a clear rationale for this study and links directly with the research aim.

This paper aims to explore the role of coaching in mergers and organisational changes in the housing association sector, while critically reviewing literature on coaching, organisational change, housing associations and mergers and exploring the experiences and perceptions of external coaches and housing officials with respect to learning and development in the sector.

Coaching field is in the process of building their own research bases by drawing on related disciplines that have an established theoretical grounding, such as adult learning, psychology and behavioural sciences (Ehrich et al., 2001; Grant, 2005; Cox,

International Journal of Management and Applied Research, 2017, Vol. 4, No. 3 
2006; Orenstein, 2007; Rogers, 2012). In the adult learning context, coaching supports self-reflection, which leads to self-awareness, self-acceptance and self-discovery (Griffiths, 2005); reflection is therefore the central process of transformative learning, and may result in transformational change (Mezirow, 1991). The relationship between transformational changes in the housing association sector in view of the potential demand for the learning, development and transformation of housing officials has not been examined.

This paper seeks to contribute to theory development in the fields of coaching by presenting a time line model of merger process. It also adds to social identity theory (Tajfel and Turner, 1979), the transformational change model (Anderson and Anderson, 2001) and team coaching. At a practical level, the findings will be of value to housing officials involved in managing future mergers. It will also inform the practice of coaches working in the housing association sector.

The study is set in the context of housing associations in the UK. Data was collected from three separate groups: coaches with extensive experience of providing coaching and mentoring in the housing sector; housing executives at director to chief executive levels, all involved in housing association mergers between January 2011 and December 2012; and (3) housing officers up to assistant manager level, all involved in housing association mergers.

A Chartered Institute of Personnel and Development (CIPD) report (2013) argued that an organisation's success was attributed to the skills of its leadership. However, the report noted that 48 per cent of the respondents identified a skills deficit in coaching and mentoring areas, whereas 47 per cent thought the leaders 'lacked the ability to manage change' (p. 23). The CIPD report did not present a skills deficit specific to the housing sector, but the high level of mergers and resultant organisational change was noted, and it would be useful to examine whether the benefits of coaching and mentoring have been recognised by housing associations, especially during periods of significant change, such as mergers.

It is well known that there is a rising popularity of coaching and mentoring in workplace settings, but at the same time, empirical evidence of the impact of coaching and mentoring on staff is lacking (Garvey and Alred, 2000; Garvey, 2004; Joo, 2005; Clutterbuck, 2008). There is limited scholarly literature covering the use of coaching in the housing association sector. This study seeks to make a contribution to closing the empirical gap in this area.

Coaching is a relatively young profession, and the evidence base of research is still growing. Conversely, research on mergers has matured and different theories have been developed. Seo and Hill (2005) identify six theories to explain the problems in managing mergers and acquisitions: anxiety theory, social identity theory, acculturation theory, role conflict theory, job characteristic theory and organisational justice theory. In contrast to merger theories, there is an acute dearth of housing theories. This represents an opportunity for studies that bring together different aspects of coaching in the housing sector, and its impact on housing association mergers.

Research grounded in the perspective of housing officials and external coaches will allow the development of theories around how coaching is being used in the housing

International Journal of Management and Applied Research, 2017, Vol. 4, No. 3 
sector, and will provide insights into their impact during housing association mergers. This will inform theory and practice in relation to coaching and mentoring in housing associations, and will add to some small but important work on housing association mergers.

\section{Housing Associations}

There are over 1,500 housing associations of various sizes in the UK, which manage more than 2.4 million homes (Gulliver et al., 2011). The term 'housing association' was not in common usage until the mid-1930s (Malpass, 2000), when this generic term became known with the introduction of the Housing Act 1936. The term 'housing association', embraces charitable housing trusts (including almshouse trusts) and 'public utility' housing societies (including housing cooperatives) (Gulliver et al., 2011). The housing association sector in the UK is made up of diverse non-profit making organisations including charities, limited companies and industrial and provident societies (Lam, 2009). This study uses Best's (1991) definition of a housing association:

[A] not-for-profit housing provider, which is controlled by a voluntary committee and is constitutionally independent of government (Best, 1991: p. 142).

Many housing associations claim to have deep historical roots (Gulliver et al., 2011) but this history is discontinuous (Malpass, 2000; Gulliver et al., 2011). Malpass (2000) claims that the connection between modern housing associations and their roots in the nineteenth century has been taken for granted rather than supported by evidence. Morris (2001) states that in nineteenth-century England, decent working-class housing was developed by a group of market institutions called model dwellings companies (MDCs). According to Malpass (2000), the Society for Improving the Conditions of the Labouring Classes had built four housing schemes in London between 1925 and 1935, and in the mid-1960s the society had 361 dwellings when it merged with the Peabody Trust. This could be argued to be the first merger of housing associations.

\section{Development of Housing Associations}

It took over a century for housing associations to develop into their present-day shape and structure. Gulliver et al. (2011) asserted that housing associations were established in four waves:

The first wave (pre-1914): Consisting of 5 per cent philanthropy, voluntary housing organisations, MDCs, co-partnership societies and Octavia Hill-style management philosophies.

The second wave (1920s and 1930s): The foundation of a range of 'front-line' housing societies and trusts under the legal banner of 'public utility societies'.

International Journal of Management and Applied Research, 2017, Vol. 4, No. 3 
'Housing society' becomes the term of preference for most, although the term 'housing association' is introduced by the Housing Act 1936.

The third wave (1960s and 1970s): The emergence of new 'social action' associations, which were involved in urban regeneration and received state funding, exemplified by the Housing Act 1974.

The fourth wave (1980s onward): The creation of Registered Social Landlords (RSLs) following the stock transfer from local authorities as per the Housing Act 1988.

These waves are reflective of the economic cycle, which impinges on non-profit as well as for-profit organisations (Van Bortel et al., 2010). In the case of housing associations, large-scale changes to their organisational structure can be seen as transformational. Rafferty and Griffin (2006) described transformational change as a significant shift in the basic aspects of an organisation. They argue that transformational change affects 'core systems, traditional ways of working, values, structure and strategy' in an organisation (p. 1155). A number of housing associations have gone through such transformational change, according to their websites, including: Gateway Housing Association (London), Knightstone Housing Association (Weston-Super-Mare), Orbit Group (Coventry), Sadeh Lok Housing Group (Yorkshire and Humber), St Vincent's Housing Association (Manchester) and Glasgow Housing Association (Glasgow). Wilcox and Perry (2013) highlight the need for transformational change for housing associations to meet the challenges posed by welfare reforms, economic austerity, changes in government policy and financial pressures.

Because of their significant effect on systems, structures and strategies, the mergers of housing associations can be classified as transformational changes. Mergers between housing associations appear to be a common phenomenon. Merrick (2005) observed that in 2005 a large number of housing associations were seeking rule changes to allow them to merge or set up new groups. Following a series of mergers, 95 per cent of the social housing stock is managed by the largest 390 housing associations (Gulliver et al., 2011).

The motives for housing association mergers, according to Merrick (2005), include gaining economies of scale and the ability to influence the national housing agenda by virtue of size. Therefore, the size of housing associations is an important factor in: lobbying and influencing the policy agenda; cost savings; and remaining competitive in a new era. Organic expansions take years, while mergers seem to offer a quick route to obtaining the desired volume and weight.

Housing associations reflect a unique context owing to their constitutional status. Mullins (2010, p. 49) suggests that housing associations could be regarded as the 'distinct uncle' of the third sector in England, because of their experience of forty years of capacity building, struggles around combining public sector delivery while preserving some independence and shifting from charity to social entrepreneurial models. The housing departments of local councils were funded by the tax payers, led by elected councillors and managed by civil servants. In their journey of transition,

International Journal of Management and Applied Research, 2017, Vol. 4, No. 3 
housing departments were set up as Arm's Length Management Organisations (ALMOs) to provide housing services on behalf of the local councils. These ALMOs were not-for-profit organisations, fully owned by the local councils and operated under the terms of management agreement. However, later on housing associations became independent of the local councils. Housing associations now have diverse boards of directors and some are raising funds on the open market through the issue of bonds, although grant funding from the government remains an important source of finance. This hybrid financial model places housing associations squarely between the state and the market (Mullins, 2010). Therefore, literature on coaching and mentoring in the public and private sectors will be included in the next chapter.

Pawson and Sosenko (2012: p. 2) note that housing associations are 'reshaping' their organisational status by allying themselves or merging with other similar bodies. They identify three modes of business combinations in the housing sector:

1. The initial establishment or enlargement of a 'group structure' involving two or more previously unrelated housing associations.

2. Two or more - existing but previously unrelated - housing associations come together to form a single entity.

3. A group consolidation - where previously established housing groups are 'collapsed' into a new unitary entity (Pawson and Sosenko, 2012: p. 7).

The definition of a 'housing association merger' in this study incorporates all these three modes of business combinations. A housing association merger is defined as:

An arrangement in which a housing association joins an established housing group, or two or more previously unrelated housing associations form a new housing group, or two or more previously established housing groups collapse into a single housing group.

\section{Financial Pressures on Housing Associations}

The recent economic downturn and changes in government policy appear to have had far-reaching consequences for the housing sector in the UK (Mullins, 2010; Gibb and O'Sullivan, 2010; Robinson, 2013; Wilcox and Perry, 2013). Wilcox and Perry (2013) refer to the Chancellor of the Exchequer's intention to reduce the fiscal deficit with spending cuts and increased taxation, and they describe the present time as 'an era of unprecedented spending cuts' (p. 6). They claim that housing associations are operating in an increasingly difficult environment, as changes in government policy have brought both immediate and long-term challenges. Housing associations are about to see the impact of policy changes and welfare reforms on their income streams, while many tenants fear the impact on their lives and aspirations, according to Wilcox and Perry (2013). The papers discussed below highlight the challenges faced by housing associations at present. This study is based in England, but the papers by Gibb and O'Sullivan (2010) and Gibb (2011) have focused on Scottish housing associations. Even though Scottish housing associations are subject to the devolved housing policy of the Scottish government, the reduction in grant funding by the UK government has a UK-wide impact. It is not the intention of this study to examine the motives for

International Journal of Management and Applied Research, 2017, Vol. 4, No. 3 
housing association mergers. Rather, this section provides the context of circumstances under which housing associations might enter into mergers.

In his article examining the government's reform agenda, Robinson (2013) describes it as a radical programme that will change funding and tenancy arrangements in the social housing sector. Funding for new build has been drastically slashed, and housing associations will be expected to make up the financial shortfall through borrowing. However, landlords will be allowed to charge a higher rent. The affordable rent charged by landlords on new tenancies could be up to 80 per cent of the local market rent. Robinson (2013) raises a concern that the higher rent might be unaffordable to some tenants. Hence, housing associations might experience a reduction in rental income, additional recovery costs and a strain on tenant-landlord relations.

Gibb and O'Sullivan (2010) observe that the funding models in the UK are unsustainable, and as a result of the credit crunch, housing developers are often left with semi-finished properties and unsold homes on their balance sheets. Despite the low risk of lending to social housing, the supply of new finance has largely dried up. So innovative thinking around new funding models for property development in regeneration areas is required. Some recent policy innovations, according to Gibb and O'Sullivan (2010), include asking housing associations to buy up unsold new homes and expanding shared equity schemes to support first-time buyers. They assert that only the largest and financially strongest housing associations (specifically, RSLs) have sufficient collateral to justify borrowings, or have the ability to raise funds through alternative sources, such as bond issue. The paper did not identify how the housing associations could become larger and financially strong enough to benefit from the alternative funding sources suggested by Gibb and O'Sullivan (2010). They do, however, use as an example the alliance of a number of local housing associations in the Scottish Highlands, named The Highlands Housing Alliance, established as a development vehicle to build new, predominantly affordable housing. By virtue of their size, the housing associations within the alliance can collectively secure a housing association grant, whereas individually the housing associations would not qualify in their own right. The model appears to be working in a small part of Scotland, but its applicability across Scotland, never mind across the UK, has not been tested. Nevertheless, this could be the beginning of a new wave of business partnerships.

In a later paper Gibb (2011) critically evaluates the affordable housing policies in Scotland. He acknowledges that Scottish housing policy is devolved, but the wider context remains in large part set by Her Majesty's Treasury and the UK government (Gibb, 2011: p. 358). As a result of the financial crisis, capital housing grants for Scottish housing associations to spend on new build have been significantly reduced from $£ 67,000$ to $£ 40,000$ per housing unit. Gibb (2011) questions whether in the wake of reduced grant levels 'housing associations can remain genuinely social in terms of rent levels' (p. 362); as a result of this, the housing association sector appears to be moving into an uncertain future. He predicts that some housing associations would forge partnerships with pension funds or private sector partners, whereas others might inevitably become a target for consolidation or takeover. Gibb (2011) concludes that housing associations are the main 'losers' (p. 365), as they will have to redesign their business models to reflect grant reductions. Even though the paper is written in the

International Journal of Management and Applied Research, 2017, Vol. 4, No. 3 
Scottish context, it appears to portray an austere picture of the situation in which housing associations in the UK find themselves.

In summary, the studies discussed in this section highlight the potential impact of the economic situation in the UK and the housing-related decisions taken by the present government. It seems that a lack of resources - that is, grants and capital funding for new build - would affect housing officials and their tenants. The ability to influence the housing agenda and to make efficiency savings through economies of scale appears to be driving housing association mergers, as noted in the previous section. Additional financial pressures and the emergence of strategic alliances as discussed in this section indicate that housing association mergers are expected to continue. Therefore, by exploring the role of coaching and mentoring in housing association mergers and transformational change, this study seeks to inform housing officials as well as coaching and mentoring practitioners. Coaching and mentoring, with reference to this study, are discussed in the next section.

\section{Coaching in Context}

There are various definitions of the coaching process as perceived by different researchers. Grant (2001) points out that the definitions vary in their degree of clarity and succinctness. Joo (2005: p. 468), after reviewing all the definitions in previous literature, defined coaching as 'a process of a one-on-one relationship between a professional coach and an executive (coachee) for the purpose of enhancing the coachee's behavioural change through self-awareness and learning, and thus ultimately for the success of [the] individual and [the] organization'. Hamlin et al. (2008) reviewed empirical literature associated with coaching using a neo-empiricist stance and critical realist ontology. They collated definitions of coaching, mainly taken from two studies carried out by Grant (2001) and Joo (2005), and additional definitions they came across from their own literature research. These definitions differ in terms of the complexity and comprehensiveness of the coaching process. Hamlin et al. (2008) listed thirty-seven coaching definitions, but in my view, just eight of these definitions capture the breadth of coaching activities such as empowerment, performance enhancement, transformation, self-directed learning and personal growth that are considered relevant for this study. These eight definitions are shown in Table 2.1. As presented by Hamlin et al. (2008), the bold refers to the intention and purpose, whereas the italics refer to the coaching process.

Table 2.1: Examples of Coaching Definitions Selected from Hamlin et al. (2008)

\begin{tabular}{ll}
\hline Definitions, purposes and processes & Authors \\
\hline Coaching ... refers to the managerial activity of creating, by communication & Evered and \\
only, the climate, environment, and context that empowers individuals and & Selman (1989) \\
teams to generate results. &
\end{tabular}

Coaching is a process that enables learning and development to occur and

Parsloe (1995) performance to improve.

Coaching is, exclusively, a process focusing on enhanced performance.

Burdett (1998)

International Journal of Management and Applied Research, 2017, Vol. 4, No. 3 
A coach is a person who facilitates experiential learning that results in

Hudson (1999)

future-oriented abilities and who is trained and devoted to guiding others into increased competence, commitment and confidence.

[Coaching] is a collaborative, individualized relationship between an executive and a coach, the aims of which are to bring about sustained behavioural change and to transform the quality of the executive's working and personal life.

[Coaching] is a powerful process that supports people in releasing their true potential and in making changes in their lives.

Zeus and Skiffington (2000)

Professional coaching is a theoretically grounded, systematic, goal-directed process designed to facilitate sustained change and foster the on-going selfdirected learning and personal growth of the coachee and is aimed at skills

Richardson (2004)

Grant and

Cavanagh development, performance enhancement and personal development.

Professional coaching is an ongoing professional relationship that helps people produce extraordinary results in their lives, careers, businesses or organizations. It deepens learning to improve performance and enhance quality of life.

International

Coach

Federation

(2007)

The eight definitions of coaching in Table 2.1 have elements of learning, growth, development and change. Grant and Cavanagh's (2004) definition of coaching is relied on, as it encapsulates learning, growth, development and change; these arguably might be key elements of coaching within the housing association merger and transformational change context. Therefore, in this study, coaching is defined as:

A goal-directed process designed to facilitate sustained change and foster the ongoing self-directed learning and personal growth of the coachee, aimed at skills development, performance enhancement and personal development.

Cavanagh and Grant (2004) broadly categorised it into personal and professional coaching. Personal coaching is also referred to as 'life coaching', which in the literature addresses personal as opposed to professional (work-related) issues (Portnoy, 2006; Yanovski, 2011). Personal coaching studies cover different aspects of life, including maternity coaching (Filsinger, 2012), dietary coaching (Yanovski, 2011), financial/ domestic budgeting coaching (Collins and O'Rourke, 2012) and divorce coaching (Portnoy, 2006). Since this study is set in the workplace context, the focus is on professional rather than personal or life coaching literature. Cavanagh and Grant (2004) divided professional coaching in the organisational setting into two categories: executive coaching for senior executives, and workplace coaching for non-executive employees. They claim that executive coaching focuses on strategic planning and leadership development, whereas workplace coaching aims at skill development and performance improvement. Arguably, the overall purpose of professional coaching is to develop the coachee's skills in accordance with the requirements of the job. Therefore, there are no benefits of differentiating coaching into executive and workplace coaching; all forms of professional coaching are considered relevant in this study. Organisations that integrate coaching into their staff development programmes show their intent of creating a coaching culture.

International Journal of Management and Applied Research, 2017, Vol. 4, No. 3 
Coaching culture exists in some housing associations, according to Bentley (2012). A coaching culture is defined by Clutterbuck and Megginson $(2005, \mathrm{p} .19)$ as one where, 'coaching is the predominant style of managing and working together, and where a commitment to grow the organisation is embedded in a parallel commitment to grow the people in the organisation'. Chidiac (2013) described this as embedding coaching strategically and rewarding coaching in performance appraisals in organisations. Characteristics of a coaching culture include a belief in human potential and the value of striving to unleash that potential (Rosinski, 2011). Creating a coaching culture may be important but it is a lengthy and gradual process, according to Megginson and Clutterbuck (2005). In the observation of Ralfe (2010), where a coaching culture is present, employees are less resistant to change. This may be because a coaching culture requires an ability to liaise and co-operate with others who have differing views of the organisation and of the purpose of coaching (Garvey et al, 2009). Additionally, employees have a vested interest in their own success and a passion for shared goals, which is intertwined with the success of the organisation (Ralfe, 2010). Studies about coaching cultures link individual development to corporate success. A coaching culture can improve overall organisational performance by up-skilling and empowering staff (Bentley, 2012).

Coaching cultures in the housing sector were researched by Bentley (2012). In a case study of three housing groups and an industry regulator, Bentley (2012) noted that there was a coaching culture within all three housing groups, namely; Metropolitan, New Charter and Together housing groups, whereas, the industry regulator TSA (Tenant Services Authority) had a mentoring culture. Bentley (2012) concluded that a coaching culture can be used to support staff to learn, grow and maximise their potential, which can make a significant contribution to the development of employees. It can also improve organisational performance by ensuring that employees have appropriate skills, knowledge and experience, according to Bentley (2012). She also stated that a mentoring culture can support individuals during a period of change. Garvey et al (2009) observed that there is widespread interest in creating coaching cultures but less so in creating a mentoring culture. Issues relating to coaching and mentoring cultures within housing associations are an under-researched area.

\section{Coaching in the Housing Sector}

There is some evidence that coaching is used by housing associations. Jarvis et al. (2006) provided a brief analysis of thirty-four organisations that introduced coaching and volunteered to share their experiences with the researchers. There are only two housing associations in this list: the Glasgow Housing Association and the Midland Area Housing Association. Coaching is measured and evaluated in both organisations differently.

The Midland Area Housing Association implemented a five-year business plan 'Route Map to Excellence 2003-2008'. In 2005 the Audit Commission, in their independent report, noted that 'over the past two years, the association has completely overhauled its operations to achieve significant operational and cultural change ... [including] rigorous challenge to leadership and systems to drive improvements ...

International Journal of Management and Applied Research, 2017, Vol. 4, No. 3 
[B]enchmarking with the private sector has brought a fresh perspective into the workplace ... [and] has excellent prospects for improvement' (Audit Commission, 2005). Midland AHA is now part of the Midland Heart, formed in 2006 following the merger of Keynote Housing Group (based in Coventry) and Prime Focus Housing Group (based in Birmingham). Midland Heart class themselves as one of the UK's leading housing and community investment organisations on their website (see www.midlandheart.org.uk).

The Glasgow Housing Association was considered to be a special case. The majority of tenants voted in favour of transferring housing stock from Glasgow City Council to the Glasgow Housing Association. In their case study, Kearns and Lawson (2008) argue that the Glasgow stock transfer was unique in four respects: (1) the size of the transfer - over 80,000 dwellings, significantly more than any transfer in the UK; (2) the poor condition of the stock - this included a housing debt of circa $£ 900$ million, plus $£ 4$ billion of public and private housing investment over 30 years; (3) the twostage transfer - all stock was transferred from Glasgow City Council to the Glasgow Housing Association in the first instance, and then through a second stage transfer to local communities; and (4) the stock transfer was meant to be the Scottish Executive's flagship programme, hence it was considered to have significant political importance.

The impact of coaching on the above-mentioned merged housing associations was not reported separately by Jarvis et al. (2006). The overall results of all thirty-four organisations presented in the report show an overwhelming support for the effectiveness of coaching. A total of 99 per cent of the respondents believed that coaching could deliver benefits both to individuals (coachees) and to the (sponsoring) organisation, and 96 per cent believed coaching to be an effective way to promote learning in organisations. The political and financial challenges faced by the Glasgow Housing Association, as noted by Kearns and Lawson (2008), and the operational and cultural change in the Midland Area Housing Association, reported by the Audit Commission (2005), indicate that housing associations can benefit from coaching. In these particular cases, one housing association that had chosen coaching had an ambitious agenda for organisational excellence, while the other one was faced with complex organisational and political challenges. Both organisations had experienced transformational changes, which in one case had resulted from a merger. It is not clear how far these circumstances might be true of other housing associations utilising coaching.

There is some indication that coaching can be used for the training and development of housing officials. In an exploratory research paper, Ward and Preece (2012) assert that housing leaders have experienced a transition from working in the public sector to working in the third sector. They explored the training and development of housing sector leaders using case study methodology. The study was based in the north-east of England and the participants were the senior managers - from heads of department to the chief executive officer - of an organisation that had gone through a restructure in 2010, where the training policy was driven by the organisational restructuring. The organisation had a specific training budget and encouraged employees to enhance their qualifications through accredited routes. Some participants referred to the importance of coaching, according to Ward and Preece (2012), especially the fact that senior managers had the flexibility to choose coaching as part of their development.

International Journal of Management and Applied Research, 2017, Vol. 4, No. 3 


\section{Conclusion}

The conception and evolution of housing associations is an interesting area. Social values, legislation and economic factors played an important part in the establishment and development of housing associations, but present-day housing associations seem to find themselves in a challenging situation. On the one hand there is pride in showcasing their historical roots, but on the other hand there is pressure to merge with other housing associations to become bigger and to influence the future of housing associations.

A combination of finanical pressures - including a reduction in grant funding from the government and a potential loss of rental income from tenants because of changes in legislation - is bringing small housing associations and disparate partners, such as pension funds, together. Business partnerships, strategic alliances and mergers are becoming commonly used vehicles for housing associations to stay competitive in the market.

There is an indication of the existence of a coaching culture in some housing associations. Coaching was successfully used by at least two housing associations that went through transformational change. In the case of the Glasgow Housing Association, the aim was to transfer stock to local communities, whereas the Midland Affordable Housing Association later merged with another housing group. There is no empirical evidence of mentoring in housing associations other than the Housing Diversity Network mentoring. Therefore, this study seeks to contribute to the coaching and mentoring literature in the context of housing association mergers and transformational changes.

\section{References}

1. Anderson, A.L., and Anderson, D. (2001), Beyond Change Management: Advanced strategies for today's transformational leaders. San Francisco:JosseyBass/Pfeiffer.

2. Best, R. (1991), "Housing associations: 1890-1990”, In: S. Lowe and D. Hughes (eds), A New Century of Social Housing. Leicester: Leicester University Press, pp. 142-158

3. Buono, A. F., and Bowditch, J. L. (2003), The Human Side of Mergers and Acquisitions: Managing Collusions Between People, Cultures and Organisations. Washington: Beard Books.

4. Burdett, J. O. (1998), "Forty things every manager should know about coaching", Journal of Management Development, Vol. 17, No. 2, pp. 142-152. https://doi.org/10.1108/02621719810206050

5. Cavanagh, M. J., and Grant, A. M. (2004), "Executive coaching in organisations: The personal is the professional", International Journal of Coaching in Organisations, Vol. 2, No. 2, pp. 6-15.

6. Chartered Institute of Personnel and Development (CIPD) (2013), Learning and Talent Development - Annual survey report 2013, London: CIPD.

International Journal of Management and Applied Research, 2017, Vol. 4, No. 3 
7. Clutterbuck, D. (2008), "What's happening in coaching and mentoring? And what is the difference between them?", Development and Learning in Organizations, Vol. 22, No. 4, pp. 8-10. https://doi.org/10.1108/14777280810886364

8. Collins, J. M., and O'Rourke, C. (2012), “The application of coaching techniques to financial issues", Journal of Financial Therapy, Vol. 3, No. 2, pp. 39-56. https://doi.org/10.4148/jft.v3i2.1659

9. Cox, E. (2006), "An adult learning approach to coaching”, In M. Grant and R. Stober (eds), Evidence Based Coaching Handbook (193-217). Hoboken, NJ: Wiley \& Sons.

10. Evered, R. D., and Selman, J. C. (1989), "Coaching and the art of management", Organizational Dynamics, Vol. 18, No. 2, pp. 16-32. https://doi.org/10.1016/00902616(89)90040-5

11. Filsinger, C. (2012), "How can maternity coaching influence women's reengagement with their career development", International Journal of Coaching and Mentoring, Special issue 6, pp. 46-56.

12. Garvey, B. (2004), "The mentoring/counselling/coaching debate: Call the rose by any other name and perhaps it's a bramble?", Development and Learning in Organisations: An International Journal, Vol. 18, No. 2, pp. 6-8. https://doi.org/10.1108/14777280410519554

13. Garvey, B., and Alred, G. (2000), "Developing mentors", Career Development International, Vol. 5, No. 4, pp. 216-222. https://doi.org/10.1108/EUM0000000005359

14. Garvey, B., Stokes, P., and Megginson, D. (2009), Coaching and mentoring: theory and practice. London: Sage.

15. Gibb, K. (2011), "Delivering new affordable housing in the age of austerity: Housing policy in Scotland", International Journal of Housing Markets and Analysis, 4 (4) 357-368. https://doi.org/10.1108/17538271111172157

16. Gibb, K., and O'Sullivan, A. (2010), "Housing-led regeneration and the local impact on the credit crunch", Local Economy, Vol. 25, No. 2, pp. 94-107. https://doi.org/10.1080/02690941003741085

17. Grant, A. M. (2001), Towards a psychology of coaching: The impact of coaching on metacognition, mental health and goal attainment. $\mathrm{PhD}$ paper, Macquarie University, Australia.

18. Grant, A. M. (2005), What is evidence-based executive, workplace and life coaching?", In M. Cavanagh, A. M. Grant and T. Kemp (eds), Theory, Research and Practice from Behavioural Sciences (1-12). Brisbane: Australian Academic Press.

19. Grant, A. M., and Cavanagh, M. J. (2004), "Toward a profession of coaching: Sixty-five years of progress and challenges for the future", International Journal of Evidence Based Coaching and Mentoring, Vol. 2, No. 1, pp. 1-16.

20. Grant, A. M., Curtayne, L., and Burton, G. (2009), "Executive coaching enhances goal attainment, resilience and workplace well-being: A randomised controlled

International Journal of Management and Applied Research, 2017, Vol. 4, No. 3 
study", The Journal of Positive Psychology, Vol. 4 No. 5, pp. 396-407. https://doi.org/10.1080/17439760902992456

21. Griffiths, K. (2005), "Personal coaching: A model for effective learning", Journal of Learning Design, Vol. 1, No. 2, pp. 55-65. https://doi.org/10.5204/jld.v1i2.17

22. Gulliver, K., Handy, C., and Morris, J. (2011), Beacons of Hope: The Historic Role of Housing Associations Tackling Poverty, Disadvantage and Inequality. Birmingham: Human City Institute.

23. Hamlin, R. G., Ellinger, A. D., and Beattie, R. S. (2008), "The emergent 'coaching industry': A wake-up call for HRD professionals", Human Resource Development International, Vol. 11, No. 3, pp. 287-305. https://doi.org/10.1080/13678860802102534

24. Hudson, F. M. (1999), The Handbook of Coaching. San Francisco: Jossey-Bass.

25. Jarvis, J., Lane, D. A., and Fillery-Travis, A. (2006), The Case for Coaching: Making Evidence-Based Decisions on Coaching. London: CIPD.

26. Joo, B. K. B. (2005), "Executive coaching: A conceptual framework from an integrative review of practice and research", Human Resource Development Review, Vol. 4, No. 4, pp. 462-488. https://doi.org/10.1177/1534484305280866

27. Kearns, A., and Lawson, L. (2008). "Housing stock transfer in Glasgow - the first five years: A study of policy implementation", Housing Studies, Vol. 23, No. 6, pp. 857-878. https://doi.org/10.1080/02673030802416635

28. Lam, T. Y. M. (2009), “A total change management model for successful growth of housing associations", International Journal of Housing Markets and Analysis, Vol. 2, No. 3, pp. 263-275. https://doi.org/10.1108/17538270910977554

29. Malpass, P. (2000), "The discontinuous history of housing associations in England", Housing Studies, Vol. 15, No. 2, pp. 195-212. https://doi.org/10.1080/02673030082351

30. Malpass, P. (2009). The rise (and rise?) of housing associations. In P. Malpass and R. Rowlands (eds), Housing, Markets and Policy (101-121). Abingdon: Routledge.

31. Megginson, D., and Clutterbuck, D. (2005), "Creating a coaching culture", Industrial and commercial training, Vol. 38, No. 5, pp. $232-237$. https://doi.org/10.1108/00197850610677670

32. Merrick, N. (2005). "Bigger and better?", Public Finance, 17 November 2005, [Online] Available from: http://www.publicfinance.co.uk/2005/11/bigger-andbetter-neil-merrick [Accessed on 22 March 2017].

33. Mezirow, J. (1991), Transformative Dimensions of Adult Learning. San Francisco: Jossey-Bass.

34. Mirvis, P. H., and Marks, M. L. (2003), Managing the Merger: Making It Work. Washington: Beard Books.

35. Morris, S. (2001), "Market solutions for social problems: Working-class housing in nineteenth century London”, The Economic History Review, New Series, Vol. 54, No. 3, pp. 525-545. https://doi.org/10.1111/1468-0289.00202

International Journal of Management and Applied Research, 2017, Vol. 4, No. 3 
36. Mullins, D. (2010), Housing Associations: Working paper 16. TSRC: University of Birmingham.

37. Orenstein, R. L. (2007), Multidimensional Executive Coaching. New York: Springer.

38. Parsloe, E. (1995), Coaching, Mentoring, and Assessing: A Practical Guide to Developing Competence. New York: Kogan Page.

39. Pawson, H., and Sosenko, F. (2012), "The supply-side modernisation of social housing in England: Analysing recent dimensions and impacts of the post-2007 financial crisis", Housing Studies, Vol. 27, No. 6, pp. 783-804. https://doi.org/10.1080/02673037.2012.714462

40. Portnoy, S. (2006), "Divorce coaches: A new resource for matrimonial lawyers", American Journal of Family Law, Vol. 19, No. 4, pp. 231-235.

41. Rafferty, A. E., and Griffin, M. A. (2006), "Perceptions of organizational change: A stress and coping perspective", Journal of Applied Psychology, Vol. 91, No. 5, pp. 1154-1162. https://doi.org/10.1037/0021-9010.91.5.1154

42. Ralfe, J. (2010), "Change is a constant requiring a coach", Library Management, Vol. 31, No. 4/5, pp. 291-303. https://doi.org/10.1108/01435121011046353

43. Rees, J., Mullins, D., and Bovaird, T. (2012), Partnership working. Third Sector Research Centre Research Report (no. 88). UK: Third Sector Research Centre.

44. Richardson, P. (2004), The Life Coach: Become the Person You've Always Wanted to $\mathrm{Be}$. London: Hamlyn.

45. Robinson, D. (2013), "Social housing in England: Testing the logic of reform", Urban Studies Journal, Vol. 50, No. 8, pp. 1489 - 1504. https://doi.org/10.1177/0042098012462611

46. Rogers, J. (2012), Facilitating Reflective Learning: Coaching, Mentoring \& Supervision, $2^{\text {nd }}$ ed. London: Kogan Page.

47. Seo, M., and Hill, N. S. (2005), "Understanding the human side of merger and acquisition: An integrative framework", Journal of Applied Behavioural Science, Vol. 41, No. 4, pp. 422-443. https://doi.org/10.1177/0021886305281902

48. Tajfel, H., and Turner, J. C. (1979), "An integrative theory of social conflict", In W. G. Austin and S. Worchel (eds), The Social Psychology of Intergroup Relations, California: Brooks/Cole, pp. 7-24.

49. Tosey, P., and Robinson, G. (2002), "When change is no longer enough: What do we mean by 'transformation' in organizational change work?", The TQM Magazine, Vol. 14, No. 2, pp. 100-109. https://doi.org/10.1108/09544780210416711

50. Van Bortel, G., Mullins, D., and Gruis, V. (2010), "Change for the better? Making sense of housing association mergers in the Netherlands and England", Journal of Housing and the Built Environment, Vol. 25, No. 3, pp. 353-374. https://doi.org/10.1007/s10901-010-9191-8 
Review of Coaching Culture in the Times of Change in the UK Housing Associations

Sector

51. Ward, C., and Preece, D. (2012), "Leadership development: For the 'here' and the 'now'", presented in: 13th International Conference on Human Resource Development Research and Practice across Europe, 23-25 May 2012. Portugal: University of Lusiada de Famalicao.

52. Wilcox, S., and Perry, J. (2013), UK Housing Review 2013 briefing paper. UK: Chartered Institute of Housing.

53. Willig, C. (2008), Introducing Qualitative Research in Psychology: Adventures in Theory and Method. Maidenhead: Open University Press.

54. Yanovski, S. Z. (2011), "Obesity treatment in primary care - are we there yet?", The New England Journal of Medicine, Vol. 365, No. 21, pp. 2030-2031. https://doi.org/10.1056/NEJMe1111487

55. Zeus, P., and Skiffington, S. (2000), The Complete Guide to Coaching at Work. Roseville, NSW: McGraw-Hill.

International Journal of Management and Applied Research, 2017, Vol. 4, No. 3 